\title{
CFS Prediction of Winter Persistent Inversions in the Intermountain Region
}

\author{
ROBERT R. GILLIES \\ Utah Climate Center, and Department of Plants, Soils, and Climate, Utah State University, Logan, Utah \\ SHIH-YU WANG \\ Utah Climate Center, Utah State University, Logan, Utah
}

JiN-Ho YOON

NOAA/Climate Prediction Center, Camp Springs, and Cooperative Institute for Climate and Satellites, Earth System Science Interdisciplinary Center, University of Maryland, College Park, College Park, Maryland

SCOTT WEAVER

NOAA/Climate Prediction Center, Camp Springs, Maryland

(Manuscript received 11 March 2010, in final form 27 April 2010)

\begin{abstract}
A recent study by Gillies and others of persistent inversion events in the Intermountain West of the United States found a substantive linkage between the intraseasonal oscillation (ISO) and the development of persistent inversion events. Given that NCEP's Climate Forecast System (CFS) has demonstrated skill in the prediction of the ISO as far out as 1 month, it was decided to examine the CFS forecast's capability in the prediction of such winter persistent inversions. After initial analysis, a simple regression scheme is proposed that is coupled to the CFS output of geopotential height as a way to predict the occurrence of persistent inversion events for Salt Lake City, Utah. Analysis of the CFS hindcasts through the period 1981-2008 indicates that the regression coupled with the CFS can predict persistent inversion events with lead times of up to 4 weeks. The adoption of this coupled regression-CFS prediction may improve the forecasting of persistent inversion events in the Intermountain West, which is currently restricted to the more limited time span ( $\sim 10$ days) of medium-range weather forecast models.
\end{abstract}

\section{Introduction}

During the winter season, heavy rainfall events in the western United States are known to be associated with the intraseasonal oscillation (ISO; e.g., Mo and NoguesPaegle 2005). In the Intermountain West region, a different weather event is gaining increasing attention, that is, persistent inversions. Deep inversions often develop in valleys and mountain basins and frequently lead to poor air quality and associated human health problems (Reeves and Stensrud 2009). Recently, a close linkage between the occurrence of persistent inversions and

Corresponding author address: Dr. Robert Gillies, Utah Climate Center, Utah State University, 4825 Old Main Hill, Logan, UT 84322-4825.

E-mail: robert.gillies@usu.edu the 20-40-day ISO was identified (Gillies et al. 2010, hereinafter GWB). The 20-40-day ISO is a pronounced mode in the wintertime midlatitude circulations (e.g., Horel and Mechoso 1988; Lau and Nath 1999), but, more so, its intraseasonal time scale implies that forecasting persistent inversions in the Intermountain West is somewhat beyond the $\sim 10$-day horizon of weather forecast models (GWB).

A number of studies (e.g., Weickmann et al. 1985; Mo 1999; Jones 2000) suggest that the ISO in North America is an atmospheric response to diabatic heating anomalies associated with the Madden-Julian oscillation (MJO; Madden and Julian 2005). Empirical and dynamical forecasts of the MJO exhibit skill at lead times beyond 2 weeks (Waliser 2005), including the operational Climate Forecast System (CFS) of the National Centers for Environmental Prediction (NCEP), which has demonstrated 
credible skill in predicting the $\mathrm{MJO}$ as far out as 1 month (Seo et al. 2007, 2009; Weaver et al. 2009). Additionally, the CFS shows similar skill in forecasting West Coast extreme-rainfall events during winter (Jones et al. 2009). Such circumstances, together with the inversion-ISO relationship observed in GWB, imply that the CFS may exhibit potential in predicting the inversion development with a lead time beyond that of $\sim 10$ days. These circumstances lead us to undertake an investigation of the CFS's performance skill in predicting persistent inversions for Salt Lake City, Utah.

\section{Datasets and the inversion-ISO relationship}

The CFS is a fully coupled ocean-land-atmosphere dynamical seasonal prediction system and has been operational at NCEP since August 2004. Model specifications of the CFS are detailed in Saha et al. (2006). The NCEP provides historical CFS hindcast data starting at 1981 and extending through 2008. For each predicted period, the CFS hindcast is initialized from three ensemble means (denoted by $\mu_{1}, \mu_{2}$, and $\mu_{3}$ ) of five consecutive days computed from days 10 to 14 and from 20 to 24 of a particular month, and from days 1 to 4 of the following month (cf. Seo et al. 2009). Hence, the hindcasts for $\mu_{1}, \mu_{2}$, and $\mu_{3}$ start at days 12,22 , and 2, respectively, and extend throughout the period of interest (i.e., to end on 28 February). Observed atmospheric variables were obtained from the NCEP-U.S. Department of Energy Global Reanalysis 2 (GR-2; Kanamitsu et al. 2002). Upperair soundings at Salt Lake City International Airport (KSLC) in Utah were utilized to analyze inversion conditions over the period from December 1980 to February 2008, as identified in GWB. For air quality measurements, we adopted daily observations of particulate matter of $2.5 \mu \mathrm{m}$ in diameter or smaller (PM2.5) from a Utah Division of Air Quality station in Salt Lake City (site identifier 4-035-3006). Criteria for capping and deep stable layers (Wolyn and McKee 1989) were utilized by GWB to classify two types of inversion layers: 1) a capping inversion with an inversion lid capping a mixed or unstable layer above the ground level and 2) a surface inversion with a neutral or increasing temperature profile extending from the ground level up to a certain height. The dates and classifications of inversions are summarized in GWB.

GWB established an index via bandpass-filtered (2040 days) KSLC geopotential height (hereinafter $Z_{30 \mathrm{~d}}$ ) at $300 \mathrm{hPa}$ and used the index to conduct a composite analysis for the inversion frequency and PM2.5 concentrations. The composite was made of eight phases that evenly divide the $Z_{30 \mathrm{~d}}$ "index cycle," following Knutson and Weickmann (1987). The selection of this 20-40-day

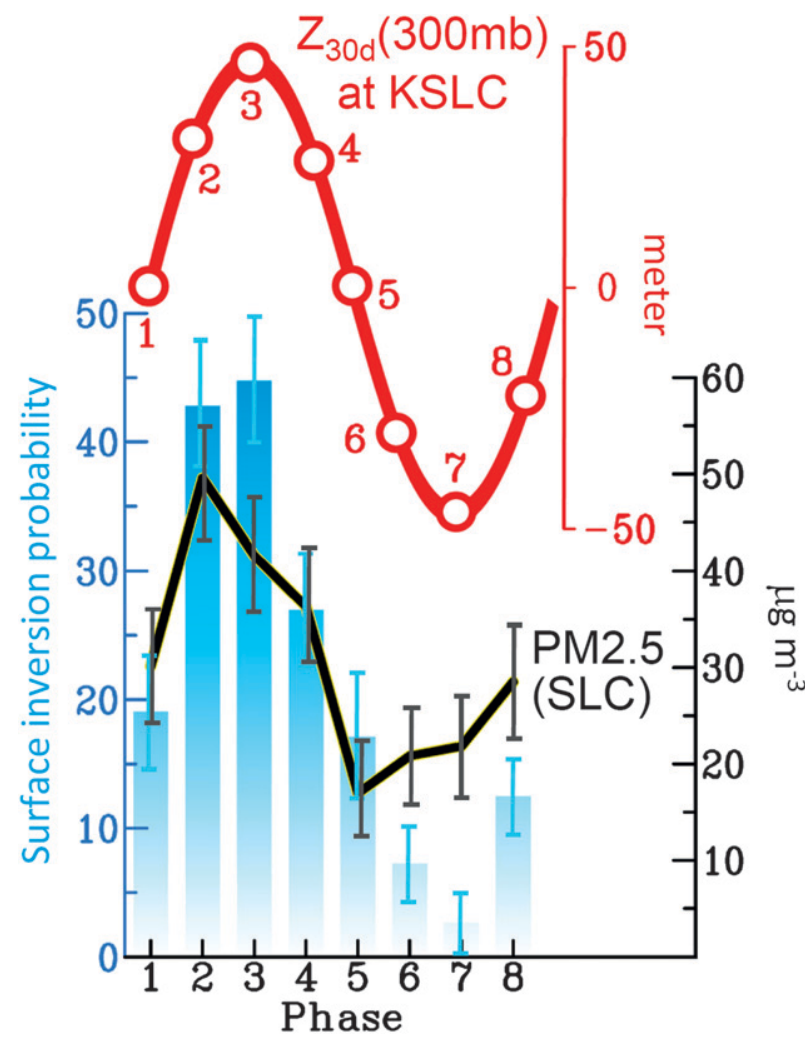

FIG. 1. Composite $300-\mathrm{hPa} Z_{30 \mathrm{~d}}$ index at KSLC and the evenly divided eight phases (red line), probability of surface inversion days (blue bars; \%), and PM2.5 concentrations at the Salt Lake City site (black line). Error bars are added for the probability and PM2.5. Modified from Gillies et al. (2010).

spectrum is due to the fact that the North American circulation seems to respond only to the high-frequency end ( $\sim 30$ days) of the MJO (GWB), corresponding to previous findings (e.g., Mo and Nogues-Paegle 2005) that the tropical-extratropical linkages of the MJO are most sensitive to shorter time scales of the MJO. Moreover, the winter ISO in the midlatitudes has been attributed to the dominant beta effect of the free Rossby wave resulting in a distinct spectral peak at 30 days (Lau and Nath 1999). It therefore seems feasible that such a midlatitude forcing would confine the variation time scale to the higher-frequency end of the MJO.

The results of GWB are summarized in Fig. 1 and show that the occurrence of surface inversions and the PM2.5 concentrations in Salt Lake City are profoundly modulated by the ISO, which is coherent with the $Z_{30 \mathrm{~d}}$ index. The surface inversion probability (SIP) in Fig. 1 was obtained from the relative frequency of surface inversions at each phase within a full cycle of the $Z_{30 \mathrm{~d}}$ index, through all identified cycles over the 1981-2008 period. Following from GWB, we used the $200-\mathrm{hPa} Z_{30 \mathrm{~d}}$ index at KSLC (since NCEP does not provide the CFS 

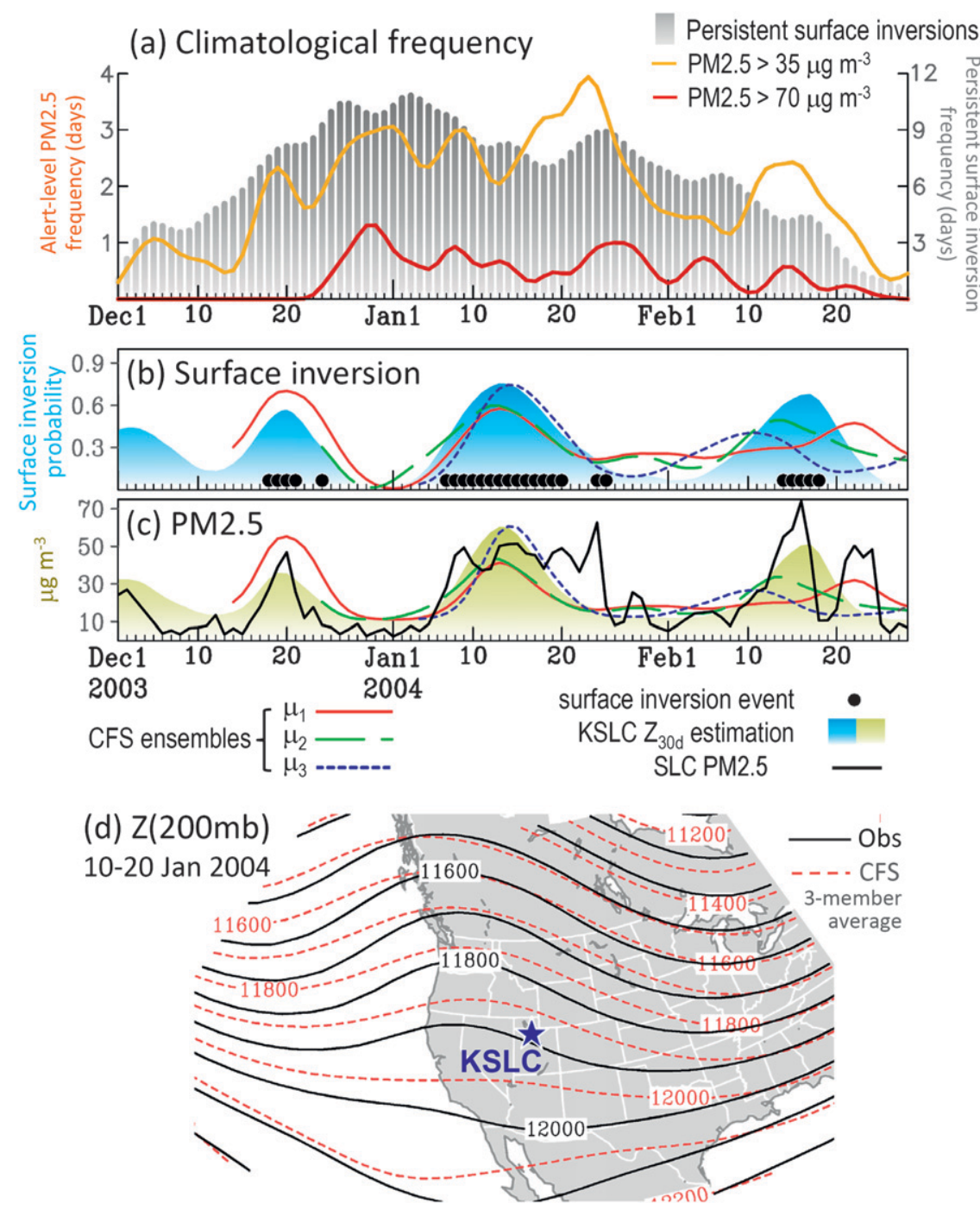

FIG. 2. (a) Climatological frequencies of persistent surface inversion events (gray bars) for the period 1980-2008 and days with PM2.5 $>35 \mu \mathrm{g} \mathrm{m}^{-3}$ (golden line) and PM2.5> $70 \mu \mathrm{g} \mathrm{m}^{-3}$ (dark red line) for the period 1999-2008. A 5-day smoothing was applied on all frequencies. (b) Estimated SIP from Eq. (1) using the KSLC $Z_{30 \mathrm{~d}}$ at $200 \mathrm{hPa}$ (blue shaded curve) overlaid with surface inversion days (dots) during December 2003-February 2004. (c) Estimated PM2.5 concentrations for Salt Lake City from Eq. (2) (green shaded curve) superimposed with the observed PM2.5 concentrations (black line). In (b) and (c) three CFS ensembles $\left(\mu_{1}, \mu_{2}\right.$, and $\mu_{3}$ ) are plotted as color lines. (d) The 200-hPa geopotential height from GR-2 (black solid contours) and the average of all three CFS ensembles (pink dashed contours) for 10-20 Jan 2004. The contour interval is $100 \mathrm{~m}$. KSLC is indicated with a blue star.

data at $300 \mathrm{hPa}$ ) and derived a second-order polynomial regression to estimate the SIP:

$$
\operatorname{SIP}=0.00001\left(Z_{30 \mathrm{~d}}\right)^{2}+0.003\left(Z_{30 \mathrm{~d}}\right)+0.237
$$

The SIP regression was derived from the composite mean $Z_{30 \mathrm{~d}}$ at $200 \mathrm{hPa}$ for each phase from all significantly strong cycles in the study (i.e., defined by the 1-standard-deviation criterion in GWB). The obtained
SIP was then regressed to estimate the PM2.5 concentration as

$$
\mathrm{PM} 2.5=52.16(\mathrm{SIP})^{2}+24.82(\mathrm{SIP})+10.54
$$

The regression models in Eqs. (1) and (2) have the largest $R^{2}$ values over linear and higher-order models. Figure $2 \mathrm{a}$ shows that the climatological frequency of persistent surface inversions (i.e., $\geq 4$ days) and the frequency of 
alert-level $\left(>35 \mu \mathrm{g} \mathrm{m}^{-3}\right)$ and unhealthy-level $(>70$ $\left.\mu \mathrm{g} \mathrm{m}^{-3}\right)$ PM2.5 concentrations in Salt Lake City are distributed mostly in the deep winter season from midDecember through mid-February. Thus, regression-model Eqs. (1) and (2) are only applicable for this time period.

As an example, the estimated SIP and PM2.5 concentrations during the 2003/04 winter are shown in Fig. 2b. A persistent surface inversion event occurred in midJanuary 2004 that lasted for 14 days (denoted by a sequence of black dots). Two shorter events also occurred around 20 December 2003 and 16 February 2004. The estimated SIP from the KSLC $Z_{30 d}$ (blue-shaded area) corresponds well to all three persistent surface inversion events, with a higher probability centered around the 14-day event. Shown in Fig. $2 d$ is the circulation pattern for this surface inversion event calculated as an average over the 10-20 January period. A ridge system is dominant over western North America with Salt Lake City situated to the east of the ridge axis; this is the typical synoptic pattern associated with prolonged valley cold pools in the Great Basin (Reeves and Stensrud 2009). Moreover, the estimated PM2.5 concentrations (Fig. 2c; yellow-shaded area) are in good agreement with observed PM2.5 (black line), and both strongly coincide with the observed persistent surface inversion events. Since Eqs. (1) and (2) use the filtered geopotential height, short-term variations in the inversion and PM2.5 estimates are inevitably smoothed out. Nevertheless, short inversion events, such as observed on 24-25 January, are coupled with higher-frequency synoptic modes that are not as crucial as the 30-day cycle and so are not captured in long-range predictions owing to the 2-week "Lorenz limit" in weather forecasting.

\section{CFS prediction skill}

To predict the SIP, we constructed the $Z_{30 \mathrm{~d}}$ index using the CFS's 200-hPa geopotential height at the grid point nearest to $\mathrm{KSLC}\left(40^{\circ} \mathrm{N}, 112.5^{\circ} \mathrm{W}\right)$. For each CFS member, 2 months of the observed (GR-2) data prior to the initial day were added to the CFS output before filtering in order to avoid "ends of data" problems associated with the second-order Butterworth bandpass filter. The predicted SIP from all three CFS ensembles for January 2004 (as denoted in Fig. 2b) captures the midJanuary persistent surface inversion event, but the CFS nearly misses the mid-February event. The predicted PM2.5 concentrations (as denoted in Fig. 2c) are similar, indicating that the CFS exhibits reasonable skill in predicting the ISO for up to 1 month, consistent with Jones et al. (2009). Further substantiation is found in the $200-\mathrm{hPa}$ geopotential height during 10-20 January 2004 averaged from the three CFS ensembles (Fig. 2d); here, the predicted ridge is phase coincident with the observed ridge, albeit slightly weaker.

Forecast skill for the synoptic circulation pattern was assessed by calculating the spatial correlation between the CFS and the verifying values of the GR-2. For the domain, as defined in Fig. $2 \mathrm{~d}\left(20^{\circ}-65^{\circ} \mathrm{N}, 150^{\circ}-80^{\circ} \mathrm{W}\right)$, the bandpassed geopotential height at $200 \mathrm{hPa}$ was added to the mean eddy geopotential height of each winter in both the CFS and the GR-2. Correlations were then computed between the two: for the CFS, we used the hindcast for December-February from 1981 to 2008. As shown in Fig. 3a, the CFS correlation skills are positive beyond 7 weeks of lead time. Using a threshold of 0.5 for the correlation skill, as was used in Seo et al. (2009), the CFS appears to predict the synoptic pattern that pertains to persistent inversion events for up to about 4 weeks. Moreover, the 1-standard-deviation range of the CFS correlation skills exceeds 0.5 through day 49 , suggesting that the CFS can occasionally predict the ISO circulation patterns for up to 7 weeks in advance.

For evaluation purposes, the CFS forecast skills were compared with various empirical forecast skills, including a principal component (PC)-lagged regression model (PCRLAG) that uses the first two PCs of the filtered geopotential height at $200 \mathrm{hPa}$, an autoregression (AR) model with the filtered geopotential height at each grid point, and the persistence forecast. These empirical forecast methods have been operational for short-term climate prediction at the NCEP/Climate Prediction Center. We used 3 months of the GR-2 data prior to the initial day of each ensemble and applied these to the empirical forecasts. As shown in Fig. 3a, the CFS skill is consistently greater than the PCRLAG and AR forecasts and is substantially better than the persistence forecast.

Next, we evaluated the CFS's prediction of persistent surface inversion events by averaging the composite SIP during peak ISO phases 2-4 (as detailed in Fig. 1), which yields a value of $35 \%$, and subsequently used this $35 \%$ as the threshold SIP in the prediction of persistent surface inversion events. Such events were defined as any consecutive 4 days of surface inversions. On either the second or the third day of a persistent surface inversion event (events identified in GWB), if the predicted SIP is greater than or equal to $35 \%$, then this event was defined as a "hit"; otherwise, the event was a "miss." If an event occurs without being predicted by the SIP (i.e., SIP $<35 \%$ ), this event was regarded as a miss. For any persistent surface inversion event lasting longer than 4 days, the hits and misses were computed independently within each 4-day period. For instance, a 7-day persistent surface inversion event would be evaluated as four individual 4-day events. After obtaining such hits and misses, we constructed a simple score, 


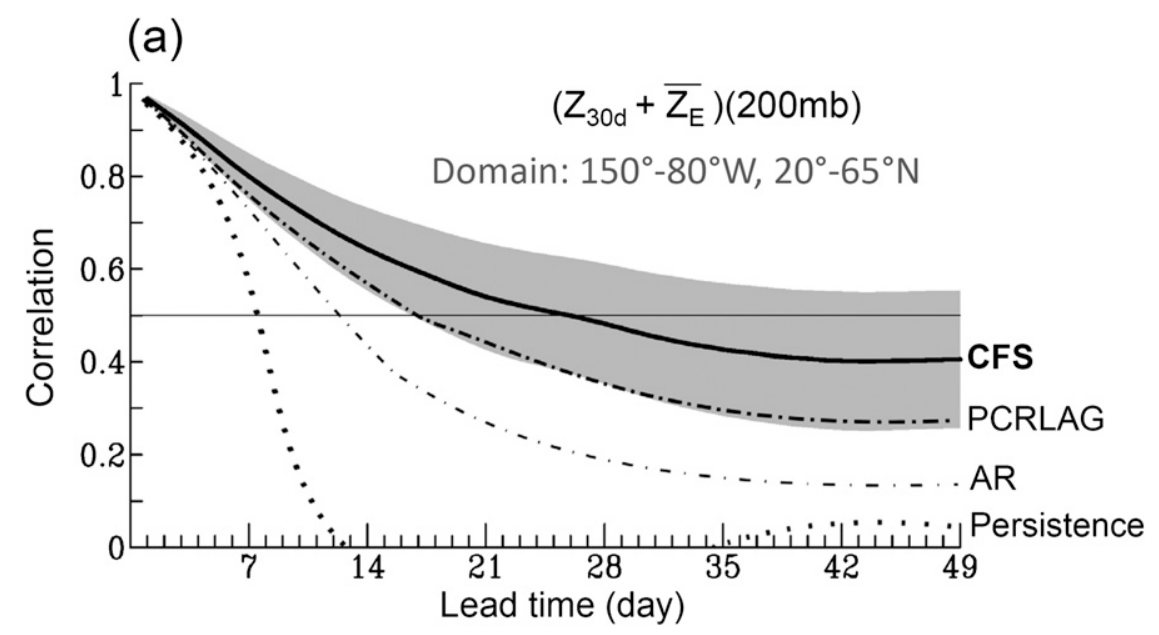

(b)

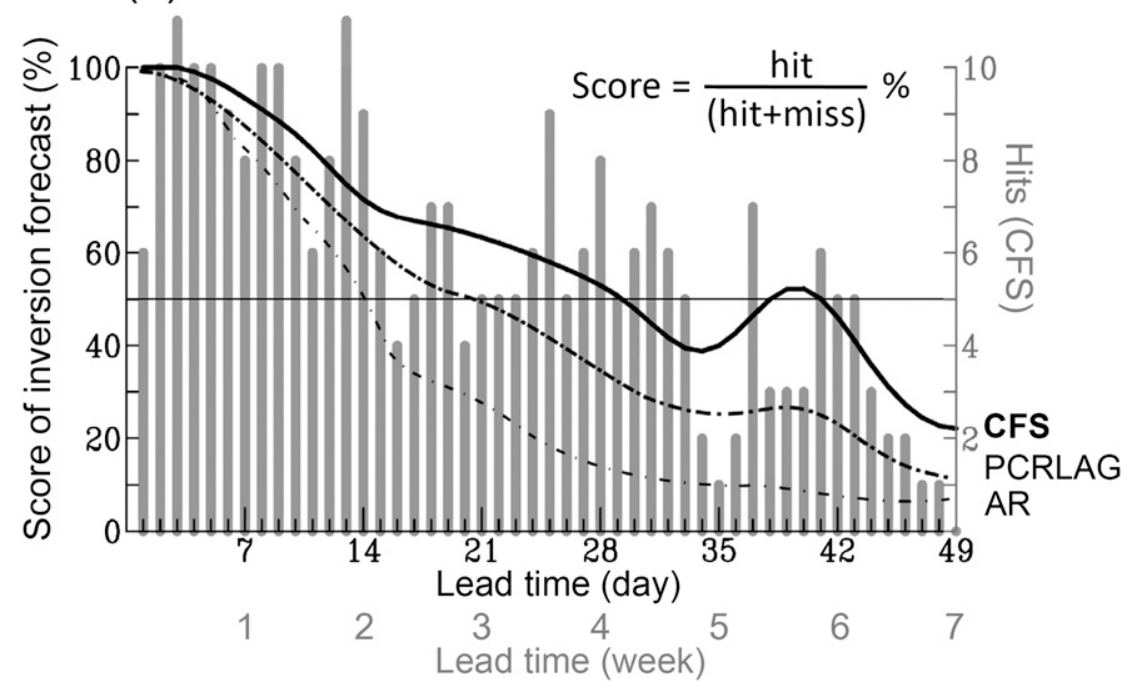

FIG. 3. (a) Correlation skill of the 200 -hPa geopotential height as a function of forecast time for the CFS, PCRLAG, AR, and persistence forecasts. The shaded area outlines $1 \mathrm{std}$ dev of the CFS skill. (b) Scores of persistent surface inversion forecasting (lines) for the CFS, PCRLAB, and AR, superimposed with the number of hits of persistent surface inversion events by the CFS (gray bars). The computation was performed over a 28-yr (1981-2008) period.

$$
\text { score }=\frac{\text { hit }}{(\text { hit }+ \text { miss })} \% \text {, }
$$

to evaluate the CFS's forecast skill for predicting persistent surface inversion events via Eq. (1).

Figure $3 \mathrm{~b}$ shows the number of hits (histogram) and the score (time series) of the CFS prediction with respect to lead time. The number of hits declines steadily with longer lead time but reveals three peaks in weeks $1-2$, $3-4$, and 5-6. This "wavy pattern" may be partly due to the 1-week interval between the three ensembles causing uneven sample sizes. Regardless, the CFS's score exhibits a similar downward tendency but remains above $50 \%$ until week 4 and rises again to above $50 \%$ near week 6. Such prediction skill is consistent with the 2004 case in which the CFS successfully predicted the persistent surface inversion events out to 5 weeks (cf. red line in Fig. 2b), yet the CFS barely predicts the midFebruary event with a similar lead time (cf. blue dashed line in Fig. 2b). These forecasts echo the $\sim 50 \%$ skill scores between weeks 5 and 6 in Fig. 3b. Nevertheless, skill scores of the CFS are consistently higher than those obtained from the empirical models, suggesting that the CFS offers a better forecast of persistent surface inversion events with a 4-week lead time. Such skill greatly surpasses the current inversion prediction procedure that relies solely on medium-range weather forecast models. Moreover, since Eq. (2) is practically a function 


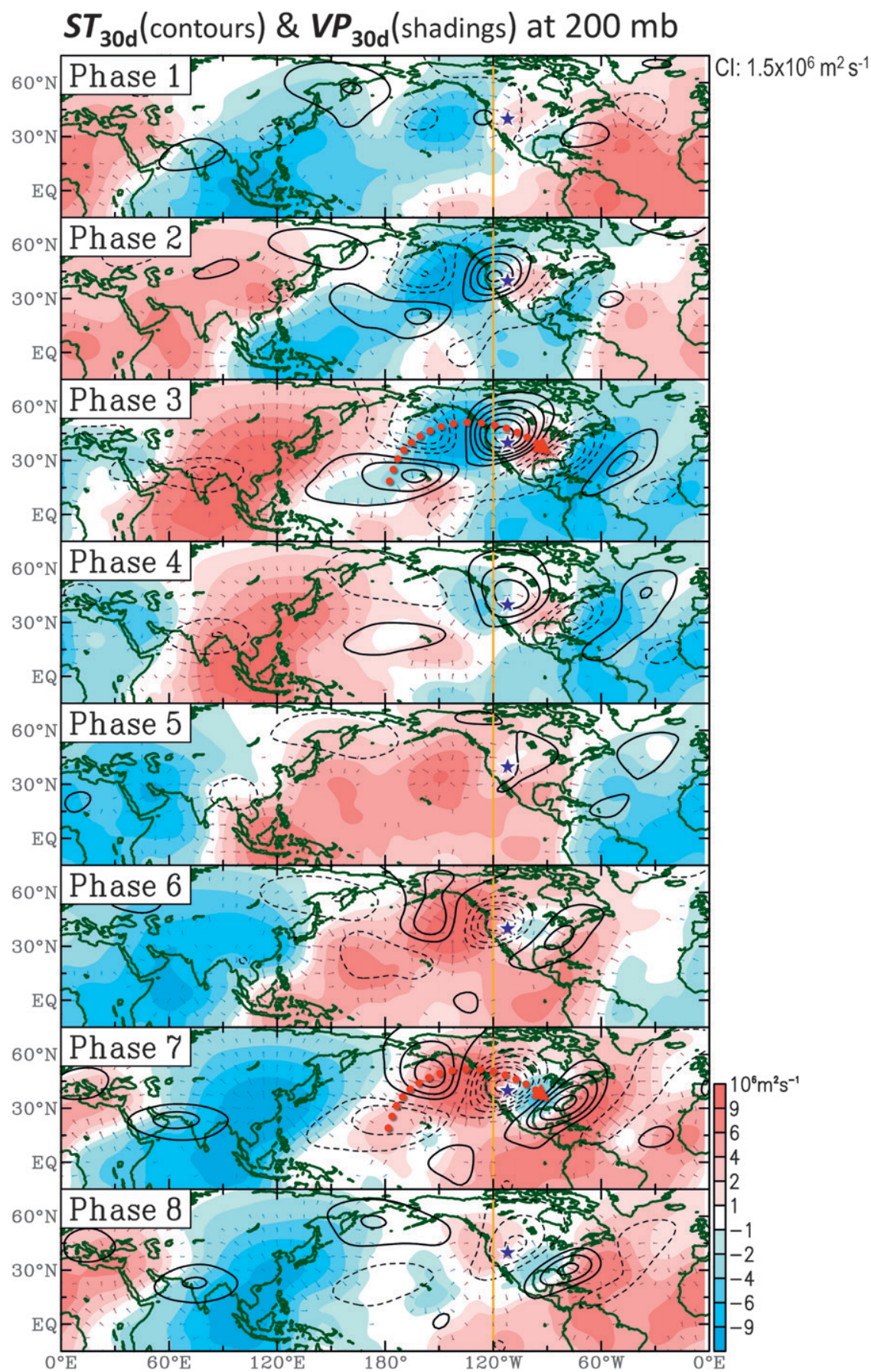

FIG. 4. Composite eight phases of the 200-hPa $Z_{30 \mathrm{~d}}$ index at KSLC in terms of the filtered streamfunction ( $\mathrm{ST}_{30 \mathrm{~d}}$; contours) and velocity potential $\left(\mathrm{VP}_{30 \mathrm{~d}}\right.$; shadings) at $200 \mathrm{hPa}$ superimposed with the divergent winds (vectors; above the $10 \%$ significance level). The calculation was based on the 28-yr GR-2 data. The contour interval (CI) of $\mathrm{ST}_{30 \mathrm{~d}}$ is $1.5 \times 10^{6} \mathrm{~m}^{2} \mathrm{~s}^{-1}$, and the zero contours are omitted. The golden line at $120^{\circ} \mathrm{W}$ roughly indicates the position of the winter mean ridge. The $\mathrm{ST}_{30 \mathrm{~d}}$ wave train is illustrated by a red dashed arrow at phases 3 and 7 . 
of Eq. (1), the results also indicate an extended predictability of prolonged, high-PM2.5 concentration events by the CFS.

\section{Discussion}

Past studies of the MJO prediction have noted that forecast skill for precipitation typically declines faster than that for the atmospheric circulation (e.g., Waliser 2005). This is attributable to precipitation's sensitivity to high-frequency weather disturbances, which have little long-term predictability. The proposed regression scheme with the CFS output, to predict persistent surface inversion events in the Intermountain West, may show relatively high skill simply because such inversion events are coupled with slow-moving circulation patterns (i.e., ridges) in contrast to unstable, highly variable precipitation systems (such as fronts). Another factor may be the CFS's documented capability in predicting tropical circulations associated with the MJO. This factor was inspected through a compiled composite of the $200-\mathrm{hPa}$ streamfunction and velocity potential, following the eight phases of the $Z_{30 \mathrm{~d}}$ index at KSLC (Fig. 1). Each phase covers 3 days centered on the second day (dates of the composite are identical to those analyzed in GWB). Prior to the composite analysis, the streamfunction and velocity potential were bandpassed with 20-40 days, denoted respectively as $\mathrm{ST}_{30 \mathrm{~d}}$ and $\mathrm{VP}_{30 \mathrm{~d}}$.

As shown in Fig. 4, the eight phases of the composite depict a clear eastward propagation of $\mathrm{VP}_{30 \mathrm{~d}}$ with predominant zonal wavenumber-1 patterns. Embedded within this typical MJO structure are a series of shortwave $\mathrm{VP}_{30 \mathrm{~d}}$ cells across the northeast Pacific Ocean and North America. These regional short-wave cells are accompanied by similarly definite, yet spatially inquadrature, wave trains of $\mathrm{ST}_{30 \mathrm{~d}}$. At phases 2 and 3 when the SIP in Salt Lake City is elevated, the $\mathrm{ST}_{30 \mathrm{~d}}$ wave trains appear to follow the classic "great circle" route of the Pacific-North America pattern (Horel and Wallace 1981), leading to a prevailing ridge in western North America. An oppositely signed circulation anomaly is also evident at phases 6 and 7. Despite the pronounced eastward propagation of global $\mathrm{VP}_{30 \mathrm{~d}}$, the regional wave trains of both $\mathrm{VP}_{30 \mathrm{~d}}$ and $\mathrm{ST}_{30 \mathrm{~d}}$ appear to be quasi-stationary. Such a feature underscores the fact that wintertime stationary waves in North America fluctuate in response to the tropical-extratropical linkages of the MJO excited by tropical Pacific diabatic heating anomalies (e.g., Kushnir 1987; Mo and NoguesPaegle 2005). These results strongly suggest that the occurrence of persistent inversions in the Intermountain West region is "phase locked" with the MJO evolution.
As a result, the CFS's skill in predicting the MJO (Seo et al. 2007, 2009; Weaver et al. 2009) likely assists in predicting the circulation systems in western North America that lead to persistent inversions.

Acknowledgments. Valuable comments by three anonymous reviewers were highly appreciated. We thank Marty Booth for preparing the PM2.5 data. This study was supported by the USDA-CSREES-funded Drought Management, Utah Project, and the Utah Agricultural Experiment Station, Utah State University, and approved as journal paper number 8186 .

\section{REFERENCES}

Gillies, R. R., S.-Y. Wang, and M. R. Booth, 2010: Atmospheric scale interaction on wintertime Intermountain West inversions. Wea. Forecasting, 25, 1196-1210.

Horel, J. D., and J. M. Wallace, 1981: Planetary-scale atmospheric phenomena associated with the Southern Oscillation. Mon. Wea. Rev., 109, 813-829.

, and C. R. Mechoso, 1988: Observed and simulated intraseasonal variability of the wintertime planetary circulation. J. Climate, 1, 582-599.

Jones, C., 2000: Occurrence of extreme precipitation events in California and relationships with the Madden-Julian oscillation. J. Climate, 13, 3576-3587.

, J. Gottschalk, L. Carvalho, and W. Higgins, 2009: Probabilistic forecast skill of extreme weather in weeks 1-4 in the United States during winter. Abstracts, 34th Annual Climate Diagnostics and Prediction Workshop, Monterey, CA, NCEP/ Climate Prediction Center-Naval Meteorology and Oceanography Command, 4.02 .

Kanamitsu, M., W. Ebisuzaki, J. Woollen, S.-K. Yang, J. J. Hnilo, M. Fiorino, and G. L. Potter, 2002: NCEP-DOE AMIP-II Reanalysis (R-2). Bull. Amer. Meteor. Soc., 83, 1631-1643.

Knutson, T. R., and K. M. Weickmann, 1987: 30-60 day atmospheric oscillations: Composite life cycles of convection and circulation anomalies. Mon. Wea. Rev., 115, 1407-1436.

Kushnir, Y., 1987: Retrograding wintertime low-frequency disturbances over the North Pacific Ocean. J. Atmos. Sci., 44, $2727-$ 2742 .

Lau, N. C., and M. J. Nath, 1999: Observed and GCM-simulated westward-propagating, planetary-scale fluctuations with approximately three-week periods. Mon. Wea. Rev., 127, 2324-2345.

Madden, R. A., and P. R. Julian, 2005: Historical perspective. Intraseasonal Variability in the Atmosphere-Ocean Climate System, K.-M. Lau and D. E. Waliser, Eds., Springer, 1-16.

Mo, K. C., 1999: Alternating wet and dry episodes over California and intraseasonal oscillations. Mon. Wea. Rev., 127, 2759-2776. , and J. Nogues-Paegle, 2005: Pan-America. Intraseasonal Variability in the Atmosphere-Ocean Climate System, K.-M. Lau and D. E. Waliser, Eds., Springer, 95-124.

Reeves, H. D., and D. J. Stensrud, 2009: Synoptic-scale flow and valley cold pool evolution in the western United States. Wea. Forecasting, 24, 1625-1643.

Saha, S., and Coauthors, 2006: The NCEP Climate Forecast System. J. Climate, 19, 3483-3517.

Seo, K.-H., J. K. E. Schemm, W. Wang, and A. Kumar, 2007: The boreal summer intraseasonal oscillation simulated in the NCEP 
Climate Forecast System: The effect of sea surface temperature. Mon. Wea. Rev., 135, 1807-1827.

W. Wang, J. Gottschalck, Q. Zhang, J. K. E. Schemm, W. R. Higgins, and A. Kumar, 2009: Evaluation of MJO forecast skill from several statistical and dynamical forecast models. J. Climate, 22, 2372-2388.

Waliser, D., 2005: Predictability and forecasting. Intraseasonal Variability in the Atmosphere-Ocean Climate System, K.-M. Lau and D. E. Waliser, Eds., Springer, 389-423.

Weaver, S., W. Wang, and A. Kumar, 2009: Representation of MJO variability in the NCEP Climate Forecast System.
Abstracts, 34th Annual Climate Diagnostics and Prediction Workshop, Monterey, CA, NCEP/Climate Prediction Center-Naval Meteorology and Oceanography Command, 4.04 .

Weickmann, K. M., G. R. Lussky, and J. E. Kutzbach, 1985: Intraseasonal (30-60 day) fluctuations of outgoing longwave radiation and $250 \mathrm{mb}$ streamfunction during northern winter. Mon. Wea. Rev., 113, 941-961.

Wolyn, P. G., and T. B. McKee, 1989: Deep stable layers in the Intermountain western United States. Mon. Wea. Rev., 117, $461-472$. 